\title{
Study of the Correlation among Junior High Students' English Learning Motivation, Attitudes and Achievements-From the Perspective of Attribution Theory ${ }^{*}$
}

\author{
Guobing Liu \\ College of International Studies, Henan Normal University, Xinxiang, China \\ Ling Zhang \\ College of International Studies, Henan Normal University, Xinxiang, China
}

\begin{abstract}
The learning motivation and learning attitude are both one's invisible factors, which can have an impact on the achievements of English learners directly or indirectly. According to the attribution theory, a proper way of attribution will play an active role in arousing the students' motivation of learning English and forming a better attitude towards learning. This research aims to analyze the correlation among the junior high students' motivation, attitudes towards learning English and achievements from the perspective of attribution theory. Through the questionnaire, classroom observation and the interview, the researcher mainly investigates the correlation among the English learning motivation, attitudes and achievements of the 112 junior high students of the two classes in Xinxiang, Henan province of China. Furthermore, the researcher also conducts an interview with three teachers in order to have a good knowledge of the correlation among the learning motivation, attitudes and the achievements. It has been found: (1)There is a positive correlation among the achievements, the motivation and attitudes towards learning English of junior high students. (2)There are four main factors which have a significant influence on the learning motivation and attitudes towards English learning of junior high students: school circumstances, classroom atmosphere, teachers and home environment. (3)In order to enhance the academic achievements of the junior high students, the strategies to motivate the students to learn English and improve their attitudes should be put forward and paid more attention to from the aspects of the school, the class, teachers and their parents.
\end{abstract}

Index Terms - motivation, achievements, correlation, attribution theory

\section{INTRODUCTION}

With the development of society and the enhancement of the economy in China, it is of profound significance for students to learn English well. To some extent, to learn the foreign language well is closely related to the non-intelligence factors, among which motivation plays an important part in English learning. Motivation is one of the most powerful factors which influences on English learning. However, in fact, the role which motivation plays in English learning is often ignored. Because of improper motivation or the lack of motivation, the prospective effects of learning English cannot be reached. At the same time, the students' attitudes towards learning should also be paid more attentions to because it plays an important part in the English learning. And the attitude towards English is a motivating factor of learning English. Therefore, it is imperative that researches on motivation should be conducted, which also conforms to the spirit of English Curriculum Standards of Compulsory Education issued by the ministry of education of China in 2011.

In general, a strong motivation of learning English and a correct attitude can help students obtain excellent achievements. However, in fact, some of the junior high students hold a wrong way of attribution, which in return, will have a negative effect on the students' motivation and attitudes towards English learning. That is to say, the way of attribution is also very important and they are interactive with each other. Therefore, we will conduct a research on the correlation among the junior high students' motivation, attitudes towards learning English and the achievements from the perspective of attribution theory. Based on the analyses of the research results, the researchers aims to have a good understanding of the junior high students, their motivation and attitudes towards learning English. And it will help the English teachers have a good design of lessons according to the current situations of the junior high students to further arouse the students' motivation and correct their attitudes towards learning English. Finally, all these can contribute to the excellent achievements of students.

\footnotetext{
* This research was supported financially in part by the Teaching Reform and Innovation Research Project of Henan Higher Education (Project No.: 2017SJGLX278).
} 


\section{LITERATURE REVIEW}

\section{A. Motivation}

Motivation is an inside agent and force to motivate people to take actions. It plays a significant role in the English learning for the learners. If the students possess a strong motivation when they are studying English, their learning effects will be more satisfactory than those with no motivation of learning English. As Jia (2007) says in his research, the foreign language learners should firstly have the motivation to learn the foreign language and only so can a kind of driving force be produced. Naturally, the learners will take actions to learn the foreign language.

Different scholars have different understandings about the concept "motivation". As Ball (1982) points out, motivation is a way to expound how people are aroused by an event, how they guide their behaviors towards the event and how they maintain the behavior. Gardner (1985a) believes that motivation is the combination of effort, desire to realize the goal of learning the language and favorable attitudes towards learning the language. Besides, there are other factors, such as attitudes towards the learning situations and the integrativeness which can have an effect on these attributes. Dornyei (1994a) holds that motivation is a many-sided concept which can be influenced by the three levels, i.e., language level, learner level and learning situation level.

All in all, different scholars have different opinions on the understanding of motivation from different aspects. We agree with the viewpoints put forward by Ball(1982) and Gardner(1985a). Motivation is an inner factor of a person. It can help to motivate someone to take actions to do something by the words or deeds from others and then maintain the behavior. During the process, the favorable attitudes should not be ignored. And it can be considered as one of the important components of motivation.

Besides, there are many scholars conducting researches on motivation. Gardner makes a clear differentiation between instrumental and integrative motivations. Instrumental motivation refers to a number of factors related to motivation coming from the external goals such as financial rewards, gaining promotion, passing exams or furthering a career. And integrative motivation occurs in the following situation that the reason for which the learners learn a foreign language is that they want to identify with the culture of people who speak that language (Williams \& Burden, 1997, p.116). From the perspective of the purpose of measurement, Gardner and his associates define motivation as the combination of desire to learn the language, motivational intensity and attitudes towards language learning in a slightly different way. They are measured by the Attitude/Motivation Test Battery (Gardner 1985a, p.177-184). Gardner (1985a) proposes a socio-educational model of language learning which consists of the following parts, and they are the learners' attitudes towards the learning situation, their integrativeness, their cultural beliefs and their motivation. Gardner and Tremblay (1994a \& 1994b) not only sustain that motivation is a dynamic process in which a great number of other variables play a role, but also believe that their model is far from being limited and it can adapt to the broader views. In order to understand the different parts involved in the motivation of learning the second language, Dornyei (1994b) puts forward a three-level classification, which includes language level, learner level and learning situation level. Vijchulata and Lee (1985) conduct a survey of students' motivation of learning English. The subjects are 1000 undergraduates from University Pertanian Malaysia (UPM for short) and they adopt questionnaires and SPSS to find out if the students in UPM are motivated in learning English and if so, what causes them to be motivated, and whether such motivation facilitates their learning process. Martin (2003) not only studies the students' motivation scale, but also the correlation among motivation and achievement, literacy and numeracy.

On the basis of the above studies, the previous researchers mainly analyze the English learning motivation from the perspectives of classifications, models and the measures of the motivation. Besides, other researchers make a research on the correlation between motivation and other factors, such as achievement, literacy and numeracy. And they usually study the English learning motivation in a quantitative way and their subjects are mainly undergraduates.

\section{B. Attitude}

Attitude is a kind of psychological phenomenon with tendentiousness. In other words, it is a kind of psychological disposition. It plays an important role in the subjective feelings and behaviors in our real lives (Tao, 2001, p. 121). Attitude plays a significant role in the learning context, which can enhance the learners' motivation of learning. Zhu (1979) first puts forward the preparation for the learning attitude in the aspect of psychological preparation for learning. He not only emphasizes that children should be fostered to have a deep love for learning and hold a serious and correct attitude towards learning, but also points that the positive attitude towards learning should be fostered continuously for a long term. Gardner (1985b) considers that learning motivation is composed of the desire to succeed, learning attitudes and degree of effort. In other words, learning attitude is closely related with learning motivation and the learning attitude is restricted by learning motivation. It is a significant factor which has a profound influence on the learning achievements.

It is obvious that there are many kinds of explanations about the attitudes. We have the same opinion with the scholar abroad Gardner and the scholar at home Tao Deqing. Learning attitudes and learning motivation are closely related with each other and both of them can contribute to the achievements of the learners. Besides, the attitude can be regarded as the invisible and internal reflection and assessment on the object. A person will develop a behavior tendency based on this reflection and assessment. And the attitude is formed once the tendency is stable. 


\section{Attribution Theory}

Fritz Heider first puts forward attribution theory in Interpersonal Relation Psychology published in 1958. In his opinion, the causes of individual's behaviors mainly lie in the two aspects which include the individuals themselves and the environment. The individual causes mainly include behavior habits, mentality, emotion, motivation, attitude and so on. While the environmental causes mainly refer to the objective and external factors which are uncontrollable. Weiner (1979) develops the theory, which will be used to expound how students treat the causality of their success and failures towards their own behaviors, learning results or other aspects. And thus he referred to it as attribution theory.

According to the previous researches, students often attribute their success and failure to the following four major causes: a person's effort, the difficulty of the task, luck, and a person's ability. Besides the above four causes, there are other causes, such as illness, mood, fatigue, and bias on the part of the person evaluating performance. It is obvious that one's effort and ability belong to the internal attribution. In other words, they are factors which arise from our insides. Luck and the difficulty of the task are considered as external factors.

Weiner (1979) makes a classification and believes it can be subdivided into the following three dimensions: locus of control, stability, and controllability. As for the locus of control, there are two types: internal and external. The students who possess internal locus of control consider that they are responsible for their own behavior and their own ability and effort, while the students who hold external locus of control think that their performance mainly comes from luck, the difficulty of the task, or other circumstances beyond their control. For the stability, he holds that causes can be either stable or unstable. There are a lot of stable causes, such as effort, ability and the difficulty of the task. And the unstable causes refer to mood and luck. For the controllability, he believes that some causes of success and failure can be controlled by the individual, such as effort and bias, while other causes are often regarded as uncontrollable, such as the ability, mood and luck.

\section{RESEARCH DESIGN}

\section{A. Research Subjects}

In this study, the subjects are 112 students from the two classes of a High School in Henan, China. They are all in Grade Seven and they are in Class A and Class B. Their ages range from 12 to 14. This school is a top school in Henan and the students are of a high level. There are 102 students who filled the research questionnaires are not valid. Among these 100 students, 6 students are chosen to have interviews to answer the open questions. Three of them are high English achievers and the other three are low English achievers. Afterwards, in order to know much more about the junior high students' motivation, attitudes towards learning as well as their ways of attribution, the researcher conducts an interview with three teachers who teach the two classes. They are the teachers who teach different subjects, ie., two for Chinese and one for art, among whom the Chinese teacher is the class adviser of Class A and the art teacher is the class adviser of Class B.

\section{B. Research Instruments}

Attribution, motivation and attitudes are one's intrinsic factors, which cannot be observed directly. However, they can be shown from other aspects, such as behaviors, speeches and so on. Therefore, this study mainly takes the following three research instruments.

The first one is questionnaire. The researcher adopts two questionnaires in this study. The first one is about English learning motivation and attitudes of the junior high students. It mainly takes Qin Xiaoqing's questionnaire of English learning motivation and Tao Deqing's questionnaire of learning attitudes, based on which the researcher makes a few adjustments according to the actual situations of the students in two classes. There are two parts in this questionnaire, which includes 27 items in total. The first part is the items from 1 to 10 and they are to measure the junior high students' motivation. And the second part is the items from 11 to 27 and they are to measure the students' learning attitudes. Each item has 5 choices and they are A, B, C, D and E. To measure each student's questionnaire better, each item stands for 1 score, 2 scores, 3 scores, 4 scores and 5 scores respectively. The second one is about attribution, which aims to measure the students' opinions on success and failure. Based on the Multidimensional Multi-attributional Causality Scale (MMCS) and Lefcourt's (1978) research, the researchers designed the questionnaire.

The second one is interview. After conducting the questionnaire, the researcher conducts an interview with the 3 high English achievers and the 3 low English achievers of the two classes in terms of the final examination. The objectives of the interview is to have a better understanding of the factors which have an effect on the English learning motivation and attitudes of the junior high students.

In order to make a further research on the students' motivation, attitudes and how the students treat their success and failure in the classes or in the examination, the researches not only conduct an interview with the students of high English achievers and the low ones but also has an interview with three teachers. They have a good knowledge of their own classroom situations and their own students.

The third one is classroom observation. From the first day of September in 2016, as an MA candidate, one of the researchers began the classroom observations. The researcher learns how to teach, how to manage the class and how to communicate with different kinds of students from their classes. At that time, the researcher finds that only a few students answer questions or take part in the classroom activities during the class. Later, the researcher obtains an 
opportunity to give lessons to the two classes for a term. During the period of giving the classes, the researcher finds that the students in Class A do not often answer the questions actively in class and they are unwilling to participate in the group work. Besides, the students are not familiar with the teacher and their relationship is not quite harmonious, which may reduce the students' motivation of learning English, while in Class B, there is a harmonious relationship between students and the teacher. They listen to the teacher carefully in class and they are ready to answer the questions that the teacher puts forward. Besides, they always take part in the classroom activities actively and discuss in their groups. They hold positive attitudes towards learning English.

\section{Research Procedures}

Firstly, the questionnaires about the motivation and attitudes towards learning English are delivered. And then the questionnaires about attribution are delivered after the final examination. It takes the students 20 minutes to hand over, fill in and recover the questionnaires. Before carrying out the questionnaires, the researcher tells students clearly that the results of the questionnaires have no relations with their term achievements and the researcher will keep the results secret. The students are informed that the results are only used to research. In this way, the students can fill in the questionnaires carefully according to their own situations.

According to the results of the final examination, the students with the results above 110 (total score is 150)are classified as the high English achievers. And the students with the results below 90 are classified as the low English achievers. And then with the help of SPSS, the researcher makes a detailed analysis of the results of the questionnaire to have a good knowledge of the correlation among the achievement, the motivation and attitudes towards learning English.

\section{RESULTS AND DisCUSSIONS}

\section{A. Achievement, Motivation and Attitudes towards Learning English}

According to the analysis of the questionnaire about the motivation and attitudes towards learning English, the researchers come to a conclusion that there is a positive correlation among the achievement, the motivation and attitudes towards learning English. That is to say, the high English achievers have a strong motivation of learning English and they hold positive attitudes towards English learning. But in general, the low English achievers have a weak motivation. Besides, they do not have a good understanding of the basic knowledge of English, which may make them hold negative attitudes towards English.

(1) The Correlation Among the Motivation, Attitudes and the Achievements

According to the analysis of the questionnaire, the researcher find that the students who have high English achievements in final examination gain good results of the questionnaire, while the students who have low English achievements gain relatively bad results of the questionnaire.

TABLE I.

CORRELATION BETWEEN THE RESUlTS OF QUESTIONNAIRE AND ACHIEVEMENTS OF STUDENTS

\begin{tabular}{llll}
\hline & & The result of final exam & The result of questionnaires \\
\hline $\begin{array}{l}\text { The result of final } \\
\text { exam }\end{array}$ & Pearson Correlation & 1 & $.706^{* *}$ \\
& Sig. (2-tailed) & & .000 \\
& $\mathrm{~N}$ & 100 & 100 \\
& Pearson Correlation & $.706^{* *}$ & 1 \\
The result of & Sig. (2-tailed) & .000 & 100 \\
questionnaires & $\mathrm{N}$ & 100 & \\
& & $* *$ Correlation is significant at the 0.01 level (2-tailed).
\end{tabular}

As is shown in table I, there is a correlation between the achievements and the results of the questionnaires. The Pearson correlation is 0.706 , which manifests that there is a positive correlation between the achievements and the results of the questionnaires. Concretely, it indicates that the greater motivation the students have, the better attitudes the students hold, thus their achievements will be better, and vice versa. Furthermore, there is an interrelationship among them. The students with a strong motivation and correct attitudes towards English learning will gain high achievements, which will in return help them strengthen their motivation and attitudes further. On the contrary, if the students have a relatively weak motivation of learning English and wrong attitudes towards English learning, there will be a situation that unsatisfactory results will be achieved and thus their English learning motivation will be reduced.

This conclusion is consistent with the one concluded before and it lays stress on the effect which the motivation and attitudes have on the English learning. Therefore, teachers should adopt all kinds of effective ways and take steps to arouse the students' motivation and guide them to have correct attitudes towards English learning. In class, the teacher should give lectures with smile all the time, and the teacher should be equal to all the students, which may build a harmonious atmosphere and close relationship with the students. All the above behaviors will help the students arouse interests in English. The teacher can also lead the students to do the warming up exercises before class, which will help the students keep a very high enthusiasm during the whole class time. More importantly, when someone makes a 
mistake in the class, the teacher should not punish them. On the contrary, teachers should encourage them to think it over and then try it again. All of these will help students enhance their motivation to learn English well.

However, we also finds that there are some students with low English achievements who gain better results of the questionnaires. It indicates that these students have great motivation of learning English well, but their achievements in the final examination are not very satisfactory. Through the long period of the classroom observation, the researchers come to know that most of these students without a good command of English knowledge on the text. The accumulation of the English knowledge is very important for their English learning. If there is no such basis, even though they have a strong motivation, their achievements will not be satisfactory. Gradually, they will lose confidence and have no motivation of learning English if they do not have the sense of achievement in English. Therefore, the teachers should pay more attention to the low English achievers. They are willing to take part in the classroom activities and they also want to learn English very well. In order to make the low achievers keep up with the general paces, teacher can slow down the speed of speaking to make sure that these students can understand what he or she says. Besides, when the teacher gives an assignment to the students, he or she had better adopt the way of layering according to the quantity and difficulty. In this way, it can help the low achievers gain more in each class according to their own actual ability. Gradually they will recover the sense of achievement and thus improve their motivation of learning English.

(2)Correlation Among the Motivation, Attitudes and the Achievements of the High English Achievers

In this study, the researchers choose the students whose achievements are above 110 to be the high achievers. From table II, it shows that there is a positive correlation among the achievement, the motivation and attitudes towards the high English achievers. The Pearson correlation is 0.578 , and it is significant at the 0.01 level. We can conclude that the students who get high achievements in the final examination have a strong English learning motivation. And they possess the correct attitudes towards learning. All these high achievers are willing to have the English lessons and they are very active during the class. With the help of the classroom observation and the interview, the researchers find that these students can preview the lessons before class, listen to the teacher carefully and take notes in class, and then recite the words and texts after class. That is to say, they develop a very good habit of learning English. Besides, their attitudes towards learning English are positive and correct. When the teacher puts forward a question, they will think it over and answer it actively. Besides, at the beginning of the term, the researcher guides all of the students of the two classes to practice calligraphy. After a period of time, these students have improved a lot and they insist on doing it from then on. Furthermore, they try to set up their goals during their learning. All these can contribute to motivate them to learn English well.

TABLE II.

CORRELATION BETWEEN THE RESULTS OF High ACHIEVERS' QUESTIONNAIRE

\begin{tabular}{|c|c|c|c|}
\hline & & The result of questionnaires & The result of final exam \\
\hline \multirow{3}{*}{$\begin{array}{l}\text { The result of } \\
\text { questionnaires }\end{array}$} & Pearson Correlation & 1 & $.578^{* *}$ \\
\hline & Sig. (2-tailed) & & .000 \\
\hline & $\mathrm{N}$ & 33 & 33 \\
\hline \multirow{3}{*}{$\begin{array}{l}\text { The result of final } \\
\text { exam }\end{array}$} & Pearson Correlation & $.578^{* *}$ & 1 \\
\hline & Sig. (2-tailed) & .000 & \\
\hline & $\mathrm{N}$ & 33 & 33 \\
\hline
\end{tabular}

(3) The Correlation Among the Motivation, Attitudes and the Achievements of the Low English Achievers

In this study, the researcher chooses the students whose achievements are below 90 to be the low achievers. From table III, it shows that there is a positive correlation among the achievement, the motivation and attitudes of the low English achievers. The Pearson correlation is 0.720 at the 0.01 level. On the one hand, it shows that the students with low achievements have weak motivation and they do not take the English learning seriously. In the class, most of these students do not listen to the teacher, even some of them do not take their English books. When doing the pair work or the group work, they are reluctant to discuss with their partners. Besides, their homework is always a mess. In other words, they do not have a correct attitude towards English learning. All these can only lead to a bad result, which will reduce their motivation in return. On the other hand, it also indicates that even though these students have low achievements, some of them possess the motivation of learning English well. Their motivation is just a little lower than that of the high achievers. Therefore, teachers should be aware that they should try to improve the students' English. Only in this way can their motivation be aroused. And gradually their good attitudes can be fostered. Therefore, the researcher often pays more attention to the low achievers. Each time they make few progresses in any aspect, the researcher will praise them in time before the students in class. And then the researcher will encourage them to continue to do it in future. All these can help them develop their interest in learning English. Additionally, the researcher is willing to make full use of the leisure time to help these students learn English, which is helpful for them to catch up with others. 
TABLE III.

CORRELATION BETWEEN THE RESULTS OF LOW ACHIEVERS

\begin{tabular}{llll}
\hline & & The result of final exam & The result of questionnaires \\
The result of final & Pearson Correlation & 1 & $.720^{* *}$ \\
exam & Sig. (2-tailed) & & .000 \\
& $\mathrm{~N}$ & 23 & 23 \\
The result of & Pearson Correlation & $.720^{* *}$ & 1 \\
questionnaires & Sig. (2-tailed) & .000 & 23 \\
& $\mathrm{~N}$ & 23 & $*$ * Correlation is significant at the 0.01 level (2-tailed).
\end{tabular}

\section{B. Factors Affecting the Motivation and Attitudes towards Learning English of Junior High Students}

There are many factors that have an influence on the motivation and attitudes towards learning English of the junior high students. On the basis of the previous research and the interview delivered by some of the students and the three teachers, the researchers hold that there are four factors which have great effects on the students' learning motivation and attitudes: school circumstances, classroom atmosphere, teachers and home environment. In the following part, the four parts will be discussed in details.

(1) School Circumstances

Environment is one of the important extrinsic factors which has a great impact on the learning. The circumstances of school, such as school tradition construction and school administration, will affect the students' emotion, learning motivation and attitudes, especially for the junior students. Williams and Robert (1997, p. 199) points that it is very necessary for the students to create and maintain a better and strong learning atmosphere, which can contribute to obtaining high achievements. With the help of the interview of the three high English achievers, the researcher finds that they are all satisfied with the school circumstances. The school attaches great importance to the culture building. According to the work arrangement, many extracurricular activities about English are held, such as English Culture Festival, English Speech Contest, English Calligraphy Competition and so on. The researcher also comes to know that the high English achievers are willing to take an active part in these activities. They think that these activities can help to improve their English and their oral English which, to some extent, can motivate them to learn English. Besides, it can help the students develop a good habit of learning English. Thus, their correct and positive attitudes towards learning English will be formed. However, by conducting the interview with the three low achievers, the researcher comes to know that these students are not interested in these extracurricular activities and they are reluctant to take part in them. They think that their English is so poor that they do not have the ability to do well in these activities. As a result, they are reluctant to spend time on the English learning, which may bring them an unsatisfactory result. Furthermore, it will reduce their motivation of learning English.

(2) Classroom Atmosphere

From the classroom observation and the interview with the students and teachers, it can be seen that the factor affecting the motivation and attitudes mainly comes from the English classes. For most of the junior high students, the classroom teaching is their main source of learning English. Therefore, the atmosphere, the classroom discipline and their classmates are very important for their learning. Another class has a relatively good learning atmosphere. The class adviser does well in elaborating their class culture. Many pictures are put up on the walls of their classroom and they are used to motivate the students to concentrate on their learning. And there are teacher's words and the best wishes for the students' learning on the blackboard at the back of their classroom. Beside the blackboard, the learning goals made by the students themselves are posted. All in all, in this way, the whole class has a good learning atmosphere. And the students will learn from each other and then study hard. In other words, it will help improve the junior high students' learning motivation and it also helps them to possess a correct attitude towards their own learning. Besides, their classroom discipline is wonderful. Thus most of them can listen to the researcher carefully. All these aspects create such a condition that there is a great atmosphere for the students themselves to learn English well. More importantly, there is such a phenomenon in Class B that the high achievers help the low achievers and their seats in the classroom are arranged according to this principle. In this way, the high achievers can be regarded as the examples of their members. At the same time, there is a competition among these groups and everyone will have a competitor. Therefore, to defeat their competitors, most of the students in Class B are willing to learn English. However, in Class A, their classroom discipline is not ideal and many of the students talks with each other in the class and do something that has nothing to do with English learning. In this atmosphere, many students cannot listen to the teacher carefully, which brings them the quite unsatisfactory achievements. Moreover, according to the interview with the low English achievers, these students argue that when other students do not listen to the class or talk with each other, they will be influenced and they are not able to listen carefully. Besides, most of them do not have a correct attitude towards learning. Therefore, their achievements will not be satisfactory. In return, their motivation of learning will be reduced. Therefore, the researcher concludes that the classroom atmosphere is essential.

(3) Teachers

Besides the factors discussed above, the teacher also plays a very important role in strengthening the students' 
motivation and attitudes towards learning English. The harmonious relationship between the teacher and the students can help to arouse their motivation of learning English. And the inculcation from the teacher is helpful to correct their attitudes towards the English learning. According to the classroom observation and the interview with the students and teachers, the researcher finds that the students who receive more help and guidance from the teacher in class and/or after class can get higher achievements. At the beginning, the researcher realizes that the subject representative of English has lower confidence in speaking English. Later, the researcher often has a talk with him and encourages him to read more and speak more. Besides, the researcher often pays more attention to him and his homework, to some extent, give him much encouragement and confidence. Furthermore, it not only helps him arouse the motivation of learning English but also helps him possess a positive attitude towards learning English. And he is encouraged to ask the researcher for help when he meets some difficulties. From then on, he is getting improvement little by little. And he achieves high scores of 118 in the final examination. By paying the visit to his home, his mother tells the researcher that he is very willing to learn English and his interests in learning English are improved greatly from the beginning of junior middle school. In addition, he can finish his homework on time and does it carefully. In the interview, the researcher knows that most of the students like learning English owing to the harmonious relationship between teachers and students. According to the arrangement of the school, the researcher pays visits to many students' homes. By the visits to their parents, the researcher comes to know that there is a great impact which the researcher has on the students' English learning. The students argue that the researcher is patient to give the lessons and always help them resolve the difficulties, which enhances their confidence and motivation of learning English. Furthermore, some of them also set the researcher as their example and thus have transformed their attitudes towards the English learning. It will help to get high achievements.

(4) Home Environments

The home environment is another important factor that cannot be ignored, which is closely related to the students' learning and growth process. According to the scientific research, the economic situation of the family, their parents' degree of education and their occupation can all influence the students' academic achievements and attitudes towards learning English. With the help of the interview, the researcher comes to know that most of the parents are busy in working and the children live with their grandparents. For that reason, some of their grandparents cannot give any guidance on their study. From the interview with the teachers, especially for the class advisers, the researcher finds that some parents of the high English achievers often call the advisers up to ask about the situations of their children and talk about their learning with the teacher. It is obvious that these parents attach great importance to the learning of their children. And as a result, their children can achieve satisfactory achievements because of their parents' attitudes towards their learning which can have a great influence on them, while the parents whose children are low achievers in learning English seldom talk with the teacher and they do not take care of their learning situations. To some extent, it will further reduce their motivation of learning. However, there is an exception that although some of the parents whose children get low English achievements also pay more attention to the situations of their children, their children's achievements are not satisfactory because they lack the basis of English learning. Some of the students are taken care of by their mothers or fathers. And in general, their mothers or fathers are responsible and considerable. Every night when their children finish their homework, they will help them check it carefully. Also, they often ask their children about the learning situations in school. They are willing to work with the teacher to help their children finish the homework and learning tasks. By paying the home visit, the researcher finds that these parents pay more attention to their children's learning. To some extent, the parents' attitudes towards learning can influence their children directly or indirectly, which will guide their children to hold a correct attitude towards learning. Thus their achievements will be improved. The researcher also finds that the students with low achievements pay no attention to the English learning. And their parents do not care about their learning situations, either. They do not ask about their marks, homework or learning tasks. Gradually, such attitudes of the parents will lead to a negative attitude of their children and their motivation of learning will be reduced.

\section{The Strategies to Improve the Junior High Students' Motivation and Attitudes towards English Learning}

Based on the above discussion, it is obvious that the strong motivation and positive attitude towards learning are very important to the students' achievements. Therefore, to improve the junior high students' motivation and attitudes of English learning is the first thing to do.

Firstly, the school should help the students build good learning circumstances by holding all kinds of extracurricular activities about English learning, which can not only help them learn English in a relaxing way but also increase their motivation of learning. These activities can be English Culture Festival, English Speech Contest, English Calligraphy Competition and so on. Most of the students will be actively involved in these activities. Through these activities, it will help the students establish a better atmosphere to learn English well. To be able to take part in them, the students will study hard to learn English well to improve their English and enhance their oral English. Bit by bit, their motivation of learning English will be aroused and increased.

Secondly, the English class is the main source for the students to learn English and the classroom is the important place for the students to study. Therefore, the classroom atmosphere should be paid more attention to. The adviser of the class should help the students build a strong learning atmosphere from the perspective of class culture and classroom discipline. In this way, it will help the students develop such a habit that they should possess a correct attitude towards learning and try their best to study hard as soon as they come into the classroom. Generally speaking, the classroom 
discipline plays an important role in their learning effects. If there is a better classroom discipline, the students' learning effects will be increased. And the better and stronger class culture can arouse the students' motivation of learning and maintain a correct attitude towards learning.

Thirdly, the relationship between the teacher and students should be harmonious and equal. The words and deeds of the teachers can have a great influence on the students' learning. Besides, the teacher should try to motivate the students at the beginning of the class in order to arouse the students' interest in learning English and maintain the motivation in the whole class. The teacher can take advantage of the several minutes before the class to guide the students to listen to an English song, do a role play, play a game or have a free talk, in order to motivate the students. In this way, it can help the students maintain a better condition that they may concentrate on their learning in the whole class. And during the class, the teacher can do some activities to encourage students to take part in and the Task-based Language Teaching approach can be used. The teacher can arrange some tasks which are related to the real life in class and it will help to guide everyone to participate in. Thus it can arouse the students' interest and motivation to learn English. More importantly, the teacher should treat the students in an equal and friendly way, which will have a significant effect on increasing the students' motivation and correcting their learning attitudes. Furthermore, the teacher should try to find out students' merits or their improvements to encourage and praise them in time, which will give them much more encouragement and motivation of learning English. Besides, more patients should be given to the students, especially to the low achievers. All these can help to arouse the students' motivation and hold a positive and correct attitude towards learning.

Last but not least, parents should cooperate with school teachers to help students achieve high achievements. The attitudes of the parents towards English learning will have a great influence on the students' motivation of learning. Therefore, the parents should pay more attention to the situations of their children's learning. And they can often ask about their learning situations and help them finish their homework every day. Besides, they should give their children more encouragement in the process of learning. All these aspects can help the students correct their attitudes towards learning and arouse them to study hard.

\section{CONCLuSiON}

\section{A. Research Findings}

This research adopts questionnaire, interview and classroom observation to study the research questions in details. And the conclusions are as below:

(1) There is a positive correlation among the achievements, the motivation and attitudes towards learning English of junior high students. In other words, they are interactional and primitive mutually for the English learners. The students with a strong learning motivation and correct attitudes towards learning English will taste and experience the pleasure of studying in the process of learning English. And later they will be more interested in learning English and work hard. Obviously, their achievements will be better, which can bring them a sense of achievement. In return, this pleasure of learning and the sense of achievement can not only help to further enhance the junior high students' motivation of learning English, but also play an important role in maintaining the correct and positive attitudes towards learning English.

(2) School circumstances, classroom atmosphere, teachers and home environment are the four main factors affecting the motivation and attitudes, which can help the students hold a correct way of attribution. The correct and proper attribution is not only helpful to arouse the motivation of learning English but also, in return, can help them maintain a correct attitude towards learning English. All these aspects can help to bring excellent achievements, which can make them possess the strong motivation of learning and hold a positive attitude towards the English learning. And it will assist them to have a proper and better way of attribution.

(3) The following ways to improve the motivation and attitudes should be paid more attention to. Firstly, it is very important for the school to establish stronger and better circumstances of studying by holding different kinds of activities, which not only offers a precious opportunity for the students to practice their oral English but also arouses their motivation of learning English. Secondly, the class culture and classroom atmosphere should not be ignored. The stronger their classroom atmosphere is, the stronger motivation the students have. Thirdly, the teachers play a significant role in the process of English learning. Their words and behaviors can affect the students a lot. Last but not least, the parents should cooperate with the teachers and pay much more attentions to their learning. The students and teachers should attach importance to these four aspects. Therefore, in order to motivate the junior high students to learn well and thus to achieve high scores, the above aspects should be taken seriously.

\section{B. Pedagogical Implications}

In order to be beneficial to the future teaching of the teachers, the researcher concludes the following three pedagogical implications on the basis of the above research findings.

(1) To arouse the students' motivation and correct their attitudes towards the English learning

According to the conclusion, the strong motivation and correct attitudes towards learning can bring excellent achievements. It is obvious that to arouse the students' motivation and correct their attitudes is important. The teachers should have a good knowledge of the basic situations of each student and take the corresponding actions to enhance the 
students' interests in learning. It will help to maintain the students' interests in learning English. Thus it can not only arouse their motivation of learning but also correct their attitudes of learning English.

(2) To pay more attention to the four main factors

The school circumstances, the classroom atmosphere, the teacher and the home environment will affect the students' learning effects directly or indirectly. Firstly, the school should think highly of the school tradition construction and holds some activities to offer an opportunity for every student to take part in them. Secondly, the teachers should also pay more attention to the classroom culture and atmosphere in the class. Besides, the teachers should better the class discipline. Thirdly, the teachers should be patient with the students and give them more encouragement and praise. And they should try to build a harmonious relationship with the students.

(3) To guide the students to have a correct and positive way of attribution

As a teacher, he or she should guide the students to have a correct and positive way of attribution to their learning behaviors and learning effects. The teachers should have a great knowledge of the way of attribution of each student. For the low English achievers, the teachers should guide them to attribute the low marks to the extrinsic factors and then help them create a chance to obtain the success, which will help them build the confidence in learning well and possess a reasonable attribution. However, for the high English achievers, the teachers should guide them to attribute the high marks to the intrinsic factors and help them realize that hard work can bring success. Furthermore, they should ask the students to believe that they are able to achieve success. Thus their motivation of learning English will be enhanced.

\section{REFERENCES}

[1] Atkinson, J. W. (1964). An Introduction to Motivation. Princeton, NJ: Van Nostrand.

[2] Andrew J. Martin. (2003). The Student Motivation Scale: Further testing of an instrument that measures school students' motivation. Australian Journal of Education, Vol. 47, No. 1, 88-106.

[3] Ball, S. (1982). Motivation. In H. E. Mitzel, J. H. Best, \& W. Rabinowitz (Eds.), Encyclopedia of Educational Research (Vol. 3 , 5th ed., pp. 1256-1263). New York: Free Press.

[4] Boosakorn Vijchulata and Gan Siowck Lee. (1985). A Survey of Students' Motivation for Learning English. RELC Journal 30(1): 258-281.

[5] Csikszentmihalyi, M. and J. Nakamura. (1989). The Dynamics of Intrinsic Motivation: a study of adolescents. In C. Ames and R. E. Ames (Eds.) Research on Motivation Education, vol. 3, Goals and Cognitions. London: Academic Press.

[6] Dweck, C. S. (1986). Motivational processes affecting learning. American Psychologist, 41, 1040-1048.

[7] Dornyei, Z. (1994a). Motivation and motivating in the foreign language classroom. The Modern Language Journal, 78(3): 273-23.

[8] Gardner, R. C. (1985a). Social Psychology and Second Language Learning: the role of attitudes and motivation. London: Arnold.

[9] Gardner, R. C. (1985b). Social Psychology and Language Learning: the role of attitudes and motivation. London: Edward Arnold.

[10] Gardner, R.C., Lambert W E. (1972). Attitudes and Motivation in Second Language. Rowley, Mass: Newbury House.

[11] Gardner, R. C. and P. F. Tremblay. (1994a). On motivation, research agendas, and theoretical frameworks. The Modern Language Journal, 78(3): 359-68.

[12] Gardner, R. C. and P. F. Tremblay. (1994b). On motivation, measurement and conceptual considerations. The Modern Language Journal, 78(4): 524-540.

[13] Jia Guanjie. (2007). Foreign Language Educational Psychology. Nanning: Guangxi Education Press.

[14] Marion Williams \& Robert L. Burden. (2000). Psychology for Language Teachers: a Social Constructivist Approach. Beijing: Foreign Language Teaching and Research Press.

[15] Tao Deqing. (2001). The Theory and Research on Learning Attitudes. Guangzhou: Guangdong People's Press.

[16] Weiner, B. (1979). A theory of motivation for some classroom experiences. Journal of Educational Psychology, 71, 3-25.

[17] Williams, M. \& Robert L. B. (1997). Psychology for Language Teachers. Cambridge: Cambridge University Press.

[18] Zhang Chunxing. (2003). Educational Psychology. Hangzhou: Zhejiang Education Press.

[19] Zhu Zhixian. (1979). Child Psychology. Beijing: People's Education Press.

Guobing Liu was born in Huaxian County of Henan, China. Now he is an associated professor and EFL teacher at the College of Foreign Languages, Henan Normal University. He studied in Chinese National Research Center for Foreign Language Education, Beijing Foreign Studies University from 2010 to 2013 and received the doctoral degree in corpus linguistics and computational linguistics there. In recent years, he published several books and more than twenty academic papers in the academic journals both home and abroad. His academic interests include corpus linguistics and foreign language teaching.

Ling Zhang was born in Xinxiang, China in 1992. She received her master's degree in English Teaching from Henan Normal University in 2017. She is currently an English teacher in The Affiliated Middle School of Xinxiang Broadcasting and TV College, Xinxiang, China. Her research interests include applied linguistics and EFL teaching for middle school students. She published several papers in the academic journals. 